\title{
Skjerming i akuttpsykiatrien
}

BAKGRUNN Skjerming er et tiltak som benyttes hyppig i psykiatriske døgnposter som en forlengelse av miljøterapien. Samtidig er metoden omdiskutert klinisk og helsepolitisk. Psykiater, tidvis psykolog, er ansvarlig for å fatte vedtak om skjerming i henhold til § 4-3 i loven om psykisk helsevern. På grunn av usikkerhet om metodens innhold og faglige legitimitet har vi gjennomført en litteraturstudie om faglig begrunnelse, praksis og effekt av skjerming.

KUNNSKAPSGRUNNLAG Artikkelen er basert på søk i nasjonale og internasjonale databaser for perioden 1930-2013.

RESULTATER Skjermingsmetoden har nær sammenheng med utviklingen av institusjonspsykiatrien, særlig akuttpostenes fremvekst, og miljøterapien. Begrepet «skjerming» dekker ulike tilnærminger, og det kunnskapsmessige grunnlaget er generelt svakt. Kliniske behandlingsstudier er i stor grad av eldre dato og trolig ikke dekkende for dagens praksis. Manglende effektstudier gjør at vi per i dag har lite kunnskap om nytten av behandling med skjerming.

FORTOLKNING Det er høy grad av diskrepans mellom skjermingsmetodens kliniske utbredelse og det kunnskapsmessige grunnlaget. For å kunne evaluere og eventuelt endre dagens praksis er det et klart behov for mer forskning på ulike typer skjerming og på effekten av skjerming.

Skjerming er et tiltak som brukes hyppig i psykiatriske døgnavdelinger, og da særlig i akuttposter. I forskriften om psykisk helsevern fra 2012 defineres det slik: «Skjerming kan innebære at pasienten henvises til opphold på sitt eget rom eller i lokaler som er atskilt fra fellesareal og pasientrom $i$ avdelingen (skjermet enhet).» Skjerming skilles i loven fra isolat ved at det ikke er en låst dør mellom pasienten og tilstedeværende personale. Det har vært diskutert om fenomenet har særnorske aspekter, selv om det foreligger overlappende internasjonal praksis (1). Skjermingstradisjonen i Norge kjennetegnes av sterk behandlingsforståelse og vektlegging av beskyttelse samt lang varighet.

I en rekke land brukes begrepet «seclusion» om en situasjon der pasienten ofte er uten personale på rommet. Forskningsresultater om «seclusion» er derfor ikke direkte overførbare til norske forhold. I likhet med «skjerming» dekker betegnelsen ulike tilnærminger, og en sammenlikning av behandlingseffekter er derfor vanskelig. Vi har ikke funnet engelske ord som direkte dekker det norske begrepet, men «quiet rooms», «openarea seclusion», «time-out» og «shielding»/ «shielding unit» synes å ligge nær $(2,3)$. I norske bidrag i internasjonale tidsskrifter har man oversatt skjerming til «seclusion» eller «segregation nursing» og skjermingsenhet til «Psychiatric intensive care unit (PICU)» eller «seclusion area» (4-7).

Det er oppgitt at $20-35 \%$ av pasientene i psykiatriske akuttavdelinger blir skjermet (8-10). I en nasjonal studie fant man 2689 skjermingsvedtak fordelt på 1406 pasienter i det psykiske helsevernet for voksne i 2009
(11). Tallene er imidlertid upålitelige, fordi bruken av skjerming varierer mellom poster og fordi forskjellig pasientbelegg kun forklarer en begrenset del av variasjonen (9).

Vi mangler en god oversikt over varigheten av skjerming. For registrerte tilfeller i 2009 varierte den fra noen få til 409 timer, og median varighet var 139,5 timer (11). En kvalitativ studie viser at skjermingstiden kan variere fra timer til måneder (1). Indikasjonene for når skjerming anses å være nødvendig synes også å variere, det dreier seg særlig om observasjon, selvskading, uro og avvikende atferd $(1,10)$.

Skjerming har vært gjenstand for faglig, juridisk, etisk og helsepolitisk debatt. Pasientenes klager på skjerming som isolasjon og tvang førte til strengere lovregulering fra 1999. Skjermingsdebatten og fagutviklingsarbeid har synliggjort svakheter ved teorien og ved utformingen av skjermingstiltak (12).

Denne oversikten er en litteraturgjennomgang av den norske skjermingstradisjonen. Vi beskriver her utvikling og begrunnelse for bruk av skjerming, analyserer metodens kunnskapsgrunnlag og drøfter implikasjoner for behandling, kvalitetsutvikling og forskning.

\section{Kunnskapsgrunnlag}

Det ble utført litteratursøk i nasjonale og internasjonale databaser (Pubmed, Medline, Cinahl, Psychinfo, Ovid Nursing, British Nursing Index, Cochrane-basen, BIBSYS og Helsebiblioteket) og i norske fagtidsskrifter for tidsrommet 1930-2013, med vekt på perioden 1970-2013. Norske søkeord var «skjerming» og/eller «tvang», «miljø-

\section{Reidun Norvoll}

reidun.norvoll@medisin.uio.no Senter for medisinsk etikk Institutt for helse og samfunn Universitetet i Oslo

\section{Torleif Ruud}

Divisjon psykisk helsevern

Akershus universitetssykehus og

Institutt for klinisk medisin

Universitetet i Oslo

\section{Torfinn Hynnekleiv}

Avdeling for akuttpsykiatri og psykosebehandling Sykehuset Innlandet, Reinsvoll

Se også kunnskapsprøve

på www.tidsskriftet.no/quiz

Podkast på www.tidsskriftet.no

> Se lederartikkel side 8

\section{HOVEDBUDSKAP}

Skjerming benyttes hyppig i psykiatriske døgnposter, særlig i akuttposter

Skjermingsmetoden er i liten grad forskningsbasert og har vært omdiskutert

Det er behov for forskningsbasert evaluering av innholdet i skjerming og effekter av skjermingstiltak 


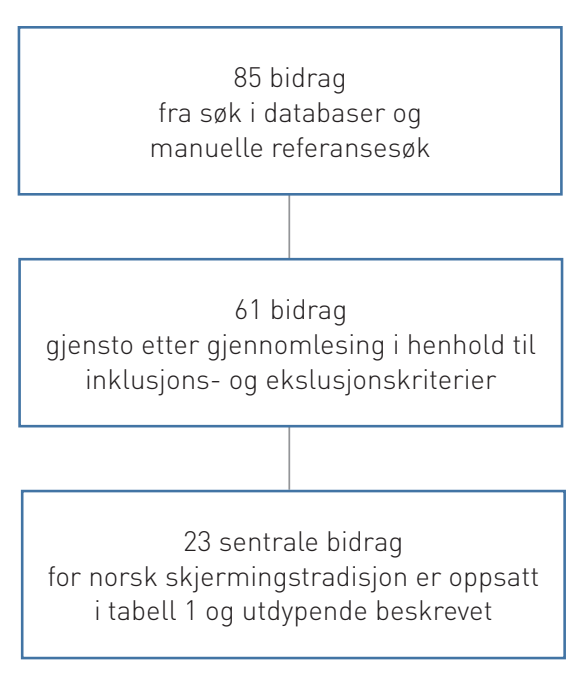

Figur 1 Utvelgelse av litteratur fra perioden 1930-2013

terapi», «grensesetting», «postatmosfære» og «akuttposter». Engelske søkeord var «seclusion», «open-area seclusion», «coercion», «isolation», «alternatives to seclusion and restraint», «containment-methods» og/ eller «psychiatric hospitals», «acute wards», «psychiatric units», «PICU».

Referanselister ble gjennomgått for å identifisere sentrale norske bidrag, og sentrale bidragsytere til den psykiatriske faglitteraturen ble forespurt. Nasjonalt senter for erfaringskompetanse innen psykisk helse har bidratt med utdypende litteratursøk om brukeres skjermingserfaringer. Vi fant én semirandomisert studie (4).

Inklusjonskriterier var forsknings- og fagbidrag som omtalte skjerming. Tverrfaglige bidrag ble inkludert for ikke å overse relevant litteratur. Enkelte nasjonale og internasjonale bidrag om miljøterapi ble inkludert, da disse har påvirket den norske skjermingstradisjonen $(13,14)$. Publikasjoner om isolat, generell miljøterapi eller postatmosfære der det ikke var eksplisitt omtale av skjermingsliknende tilnærminger ble ekskludert, det samme gjaldt bidrag uten substansiell ny kunnskap.

Som det fremgår av figur 1 fant vi 85 norske bidrag etter første sortering. Etter ny vurdering i henhold til inklusjons- og eksklusjonskriterier gjensto 61 bidrag, som ble gjennomlest. Disse består av 42 generelle bidrag der skjerming inngår implisitt som et element $i$ et annet tema, 17 spesifikke bidrag der skjermingsmetoden er hovedtema, og to bidrag med både generelle og spesifikke aspekter.

$\mathrm{Vi}$ fant ingen spesifikke bidrag om skjerming fra før 1990-årene, og ca. $75 \%$ av publikasjonene er fra etter 2000. Det var flest publikasjoner fra helsetjenesteforskning og sykepleiefaglig litteratur, fulgt av psykiatriske/tverrfaglige bidrag. Disse var i hovedsak litteraturstudier, kvalitative studier, mas- teroppgaver, fagutviklingsarbeid, generelle brukerundersøkelser og statistikk over bruk av tvang. I norske behandlingsstudier av postatmosfære har man ikke studert skjerming direkte. Det finnes dermed få spesifikke studier av skjerming. De fleste bidrag er generelle, skjerming omtales kun implisitt.

Bidragene er egnet til å gi et bilde av den norske skjermingsmetodens historiske utvikling og behandlingsfilosofi, og de gir et visst inntrykk av ansattes og pasienters vurderinger. Det gis imidlertid her begrenset vitenskapelig kunnskap om skjermingsmetodens innhold og effekter, spesielt i større utvalg. Det finnes kun én større spesifikk og systematisk behandlingsstudie av skjerming (4). Denne inkluderer fire delstudier om skjerming i forhold til interiør, lukket avsnitt og effekt ved volds- og rusproblematikk. De 23 mest sentrale vitenskapelige/faglige bidragene for skjermingstradisjonen er utdypet i tabell 1 ( 1 , $4,6-12,14-27)$.

\section{Utvikling av skjerming som begrep og metode}

Skjerming vokste frem som en sentral behandlingsmetode i Norge fra slutten av 1970-årene. Den ble først omtalt i 1977 i en lærebok om psykiatrisk sykepleie (15) og så beskrevet i en bok fra 1984 om omstillingsprosesser ved poster på Ullevål sykehus (16). Utover i 1980-årene overtok skjerming gradvis for isolat og fast vakt på pasientrommet. Deretter ble skjerming utdypet som miljøterapeutisk metode fra midten av 1980årene. Senere innflytelsesrike bidrag var Strand i 1990 (19) og et faghefte fra Psykiatrisk Opplysning i 1998 (21), der John Gunderson og medarbeideres tenkning om miljøterapi (13) var oversatt og videreutviklet. I psykiatriske lærebøker rettet mot behandlere blir skjerming gjerne omtalt stikkordsmessig, etter første gang å ha blitt berørt tidlig på 2000-tallet (28).

Fremveksten av skjerming fulgte endringene i sykehusstrukturen fra 1970-årene, da sykehusasylene og klinikkavdelingene ble integrert i spesialisthelsetjenesten som følge av lovendringen som innførte plikt for sykehusene til å yte øyeblikkelig hjelp. Klinikkavdelingene fikk økt ansvar for personer med alvorlige psykiske lidelser, og i flere fylker ble det etablert psykiatriske akuttavdelinger. Denne nyorganiseringen forte til at behandlingstenkningen om det terapeutiske samfunnet ble kritisert som lite egnet for pasienter med akutte tilstander $(16,29)$. Økt uro i døgnposten ga andre utfordringer for arbeidsmiljøet og oppfølgingen av pasientene.

Forskning på postatmosfære og på miljøterapi ved schizofreni påvirket den faglige utviklingen (16). Behandlingstenkning og organisering ble endret fra grupperettet til individorientert miljøterapi. Skjermings- metoden ble etablert som sentral ved akutt psykose - «Betingelsene må legges til rette slik at det er gode muligheter for skjerming og stimulibegrensning i akutte psykotiske forvirringstilstander» (30). Behandlingsoptimismen og begeistringen for metoden førte til skjermingstiltak også overfor andre pasientgrupper enn de psykotiske.

I de fleste fagbidrag har man forstått skjerming som en stimulusbegrensende og grensesettende metode. Skjermingsbegrepet hadde imidlertid opprinnelig en videre betydning, som «alt som kan bringe pasienten til å finne ro» (1). En annen forståelse er «beskyttelse» $\mathrm{i}$ form av det å trygge, skjerme eller ta hånd om (21). Denne oppfatningen har bakgrunn i psykodynamisk teori og Gunderson og medarbeideres fem miljøterapeutiske variabler (13), der skjerming inngår som element i beskyttelsesvariabelen. De skjelnet imidlertid ikke mellom begrepene «isolat» og «skjerming», som man gjør i Norge. Studier av miljøterapi og postatmosfære ved bruk av WAS-skalaen (Ward Atmosphere Scale) har hatt stor betydning for metodens behandlingsfilosofi (31). Det ble imidlertid ikke funnet systematisk forskning om forholdet mellom postatmosfære, miljøterapi og skjerming og om skjerming ved andre type lidelser.

I studier foretatt etter 2000 har man hovedsakelig beskrevet skjerming som tiltak, metode eller intervensjon som skal benyttes overfor den individuelle pasient. Skjerming blir også omtalt som mestringsmåte (32) og som et fysisk atskilt område for intensiv psykiatrisk behandling (4). Skjermingsmetoden skal bidra til behovet for orden på posten, skal bedre personalets arbeidsmiljø og optimalisere muligheten til å følge opp pasienten. Videre er skjerming beskrevet som deeskalerende metode og «time out» ved aggressiv atferd (6).

I nyere fagutviklingsprosjekter har man lagt mindre vekt på kontroll, fysisk makt og passiviserende restriksjoner ved skjerming til fordel for mer anerkjennende, dialogbaserte tilnærminger. Det er økt bruk av individuell og dynamisk stimulusmodulering gjennom aktivitet, åpning av skjermingsrommet og utetid $(12,26,33)$. Relasjonen mellom behandlerne og miljøpersonalet styrkes ved teamarbeid og behandlernes oppfølging av pasientene på skjermingsrommet. Videre fremheves betydningen av brukermedvirkning og inkludering av pasientens ressurser (34). Behandlingstenkningen syntes dermed å ha vært i endring, men den faktiske utbredelsen av disse trendene er ukjent.

\section{Organisering av skjerming}

Skjerming ble opprinnelig knyttet til at pasienten skulle skjermes fra gruppemøtene $i$ fellesmiljøet og kunne for eksempel foregå 
Tabell 1 Sentrale norske bidrag relatert til skjerming 1977-2013 fordelt på fag og type bidrag (N = 23)

\section{Førsteforfatter}

(referanse)

Løkensgard (15) Lærebok, sykepleie

Friis (14) Avhandling, psykiatri

Vaglum (16) Fagbok, psykiatri/ tverrfaglig

Vaglum (17) Vitenskapelig artikkel,
psykiatri

Hummelvoll (18) Lærebok, sykepleie

Strand (19)

Lærebok, sykepleie

Høyer (20)

Vitenskapelig artikkel, tverrfaglig

Bjørkly (6)

Vitenskapelig artikkel, psykologi

Haaland (21)

Hefte, tverrfaglig, inkludert psykiatri

Holte (22)

Rapport, sykepleie

Vatne (23)

Avhandling, sykepleie

Sørgaard (24)

Vitenskapelig artikkel, psykologi

Karlsson (25) Avhandling, sykepleie

Ruud (10) Rapport, helsetjenesteforskning

Vaaler (4)

Avhandling (Vaaler og medarbeidere 2005, 2006, 2006, 2011), psykiatri

Norvoll (1)

Avhandling, sosiologi $\begin{array}{ll}\text { Norvoll (12) } & \text { Rapport, helsetjeneste- } \\ \text { forskning }\end{array}$

Gamme (26) $\quad \begin{aligned} & \text { Fagartikkel, psykisk } \\ & \text { helsearbeid }\end{aligned}$
helsearbeid

$\begin{array}{ll}\text { Bjerkan(27) } & \text { Rapport, helsetjeneste- } \\ \text { forskning }\end{array}$

Husum (9) Vitenskapelig artikkel, helsetjenesteforskning

Bremnes (8) Rapport, helsetjenesteforskning

Bjørkly (11) Rapport, helsetjenesteforskning

Larsen (7) Vitenskapelig artikkel sykepleie
Undersøkelse

Litteraturstudie

Kvantitativ studie av postatmosfære og gruppebehandling spesielt ved psykose/schizofreni

Viser til internasjonal forskning og egne behandlingsstudier om miljøterapi, gruppebehandling og postatmosfære

Metaanalyse basert på fire empiriske studier av ulik miljøterapi og postatmosfære ved psykose, schizofreni og rus (herunder referanse 14 og 16)

Litteraturstudier. Liten spørreskjemaundersøkelse til 23 sykepleiere

\section{Litteraturstudie}

Kvantitativ deskriptiv studie av bruk av tvang på landsbasis

Beskrivelse av skjerming ved psykose og aggresjon illustrert ved kasuistikk

Litteraturstudie om miljøterapi

Intervjustudie med 15 ansatte i en akuttpost

Aksjonsforskningsstudie herunder refleksjonsgrupper med sykepleiere i akuttpost ved ett sykehus

Intervensjonsstudie av 190 innleggelser

Intervjustudie, herunder 11 tidligere pasienters erfaring med mani og innleggelse

Kvantitativ deskriptiv studie basert på 19 akuttavdelinger for voksne i Norge, 3572 behandlingsforløp

Kvantitative studier av et naturalistisk utvalg på totalt 118 pasienter ved ett sykehus

Litteraturstudie av skjerming 1936-2004. Etnografisk studie av to akuttposter $\mathrm{i}$ to sykehus inkludert 36 skjermingsforløp, intervjuer med ansatte og 14 pasienter

Følgeforskning av utviklingsarbeid i 6 sykehus, 10 akuttposter. Blandet metode (mixed methods)

Fagutviklingsarbeid ved Sykehuset Innlandet, Reinsvoll

Brukerundersøkelse, spørreskjema, herunder 721 pasienter om skjerming

Kvantitativ deskriptiv studie basert på 19 akuttavdelinger for voksne i Norge, 3572 behandlingsforløp

Kvantitativ deskriptiv studie av bruk av tvang på landsbasis

Kvantitativ deskriptiv studie av bruk av tvang på landsbasis

Intervjustudie av 12 pasienter og 22 ansatte i en lukket post
Omtale av skjerming

Begrepet «skjerming» omtales i sykepleie

Kun om postatmosfære. Påvirker behandlingstenkning ved skjerming

Skjerming lanseres som metode. Ingen spesifikke effektstudier av skjerming

Kun om miljøterapi og postatmosfære. Påvirker behandlingstenkning ved skjerming

Om psykiatrisk sykepleie, inkluderer litt om sykepleieres syn på skjerming

Sykepleie ved psykose med vekt på skjerming

Statistikk om skjerming

Skjerming ved aggresjon

Om miljøterapi, inkluderer skjerming

Om ansattes praktiske erfaringer med skjerming

Om grensesetting, litt om skjerming

Pasientopplevelser av tvang. Inkluderer skjerming

Om mani. Inkluderer pasientopplevelser av skjerming

Om akuttbehandling. Statistikk om bruk av skjerming

Behandlingsstudier av skjerming i forhold til interiør, vold og rus

Om skjerming i praksis. Inkluderer personalog pasientopplevelser av skjerming

Om alternativer til tvang. Inkluderer endring av behandlingstenkning og organisering av skjerming i praksis

Brukermedvirkning ved skjerming

Om pasientopplevelser av døgnbehandling. Inkluderer skjerming

Bruk av tvang, inkludert skjerming

Bruk av tvang, inkludert skjerming

Bruk av tvang, inkludert omfang og varighet av skjerming

Om tvangsopplevelser. Inkluderer skjerming 
ute i naturen. Fra 1980-årene og fremover ble imidlertid skjerming i større grad avgrenset til å være et fenomen på pasientrommet (16). Skjerming «(...) skjer ved at et personalmedlem oppholder seg sammen med pasienten i et oversiktlig og begrenset miljø (som regel pasientens rom)» (35).

Senere beskrivelser tyder på at dagens skjerming organiseres ulikt $(1,12)$. Det er imidlertid ikke systematisk kunnskap om hvilke tiltak som brukes og variasjonen på landsbasis. Skjerming kan foregå på pasientens rom i posten, på et skjermingsavsnitt eller på et eget rom (1). Skjermingen kan videre være en prosess med gradvise overganger (spesielt $\mathrm{i}$ avslutningsfasen) og av ulik grad - fra tett oppfølging ute i posten til høygradig skjerming og overvåking.

Den arkitektoniske utformingen er forskjellig, men interiøret er ofte nakent. Personalet kan sitte inne på rommet eller ute på gangen på skjermingsavsnittet. Dørene til skjermingsavsnittet kan være åpne eller lukket. Noen steder kan de være låst, slik at skjermingspersonalet må bruke nøkkel/nøkkelkort for å komme ut. Som oftest kan pasientene ikke gå ut uten personalets godkjenning.

Det beskrives både formell og uformell bruk av fysisk makt for å overholde innelukkingen. Andre typer tvang, som for eksempel mekaniske tvangsmidler og tvangsmedisinering, kan også utføres på skjermingsrommet. Bruken av ufaglærte ekstravakter varierer, likedan hvordan man vektlegger nærhet og avstand til pasientene. Det synes å være ulike syn på kommunikasjon med pasienten og på bruk av husregler, og det kan være betydelige restriksjoner.

\section{Spenninger mellom skjerming som behandling og som tvang}

I 1980-90-årene ble skjerming i hovedsak beskrevet som en behandlingsmetode og da ikke relatert til tvang, utover å være en form for grensesetting. Ofte ble skjerming forstått som en vesentlig annerledes metode enn isolat fordi personalet skal være sammen med pasientene. Spørsmålet om stengte dører ved skjerming ble ikke diskutert. Isolatet ble beskrevet som en inhuman tvangsmetode, mens skjerming fremsto som humant (16, 36). Samtidig ble faren for ensrettende stimulusdeprivasjon og regressive behandlingstilbud påpekt. Dette kunne undertrykke initiativ og håp $(1,21,35)$.

Utover på 2000-tallet fikk tvangsaspektet ved skjerming økt vekt. Forskning og fagutvikling, herunder Gjennombruddsprosjektet for reduksjon av tvang i psykiatrien, synliggjorde tvangsaspektet (24). Den tvetydige betydningen av skjerming - både som behandling og som restriksjon/tvang etter vedtak eller som frivillig tilbaketrekning fra fellesmiljøet - skapte debatt om hvorvidt lovgrunnlaget for skjerming var tilfredsstillende utformet.

\section{Virkninger av skjerming \\ for pasienter og personale}

Vi har funnet få studier om hvordan pasientene opplever skjerming. I en nasjonal brukerundersøkelse med 721 pasienter hadde $33 \%$ svært lite eller intet utbytte av skjerming, 31\% hadde stort eller svært stort utbytte (27). Svarprosenten hos tvangsinnlagte var lav. Sørgaard fant at skjerming sto for $62 \%$ av variasjonen i opplevd tvang (24).

Kvalitative studier har vist at pasientene har blandede erfaringer. Positive behandlings- og omsorgselementer er trygghet ved personalets nærvær, fast personalkontakt, ro og god hjelp til å få dekket sine behov $(1,7$, 22). Noen opplever skjermingen som hjelp ved psykosen, i tråd med behandlingsfilosofien, mens andre forteller at skjerming gir økt angst, tankekaos, klaustrofobi og selvmordstanker.

Opplevelsen av tvang ved skjerming er generelt sterkere enn behandlingstenkningen tilsier $(1,12,22,34)$. Faktorer som bidrar til tvangsopplevelser er innelukking, nakent interiør, belterom, fysisk maktbruk, passivitet og sosial isolering fra medpasienter og omverdenen. Følelsen av tvang forsterkes av militante kommunikasjonsformer og lite anerkjennende tilnærminger. Flere opplever seg møtt med for sterk grad av patologisering og/eller barnsliggjøring og kritiserer unødig bruk av restriktive husregler.

Det er gjennomført enkelte studier av skjermingens innvirkning på personalets arbeidsmiljø. Ved Ullevål sykehus førte innføringen av individrettet miljøterapi med skjerming til et bedre post- og arbeidsmilje og mindre uro og vold. Samtidig ga endringene nye typer belastninger, økt avstand til pasientene og mer kontroll. Vekt på individuelle avtaler og skjerming svekket innholdet $\mathrm{i}$ behandlingsopplegget på postens åpne del (16)

I nyere bidrag mener personalet at metoden kan bidra til å skape trygghet og være et egnet redskap for tett oppfølging av pasienten. Det er imidlertid beskrevet dilemmaer for personalet knyttet til isolering av pasienten, stor kontroll og maktbruk, rigiditet og vokterrolle under skjerming samt hyppig misnøye og verbal eller fysisk protest fra pasientene. Spenningen mellom behandling og kontroll gir stort behov for etisk refleksjon $(1,12,26,37)$. Det er usikkert hvorvidt beskrevne erfaringer gjenspeiler ulik gjennomføring av skjerming.

Innføringen av skjermingsmetoden i 1980-årene og dens økende utbredelse er liten grad blitt fulgt opp av effektstudier (4) Vaaler og medarbeidere fant at pasientene var mer fornøyd med skjermingsavsnitt med hjemmekoselig miljø enn nakent interiør, og at vanlig interiør reduserte tendensen til ødeleggelse av møbler $(4,5,38)$. De fant videre at skjermingsavsnitt ga raskere symptomreduksjon ved ruslidelser (39). Noen studier viser at skjermingsavsnitt kan gi færre trusler og mindre vold $(5,6,40)$, andre at det å bli lukket inne på et rom kan skape konflikt, aggresjon og utagering $(1,12,26)$.

Nyere behandlingstenkning og organisering av skjerming synes å kunne gi mindre bruk av metoden, økt tilfredshet hos pasienter og personale og reduksjon av konfliktnivå og utageringssituasjoner $(12,26,33)$.

\section{Diskusjon}

Denne litteraturgjennomgangen har vist at skjerming er en betegnelse som et lite presisert og som brukes om forskjellige tilnærminger og tiltak. Det foreligger knapt nok effektstudier og randomiserte studier. Skjerming integreres i stor grad i miljøterapien, men samtidig er forholdet mellom miljøterapi og skjerming utydelig. Pasientenes tilbakemeldinger, usikre effekter, nyere behandlingstrender og uklarheter om skjerming som behandling/tvang og isolering reiser juridiske og kliniske spørsmål som trenger avklaring.

En rekke andre forhold som klinikere har rapportert som vesentlige ved bruk av skjerming, er det overhodet ikke forsket på. Ett eksempel er behandling med psykofarmaka, som antas å kunne bidra til kortere skjermingstid, men som i visse tilfeller også kan tenkes å medføre et skjermingsbehov, som ved atferdsbivirkningen akatisi. De etiske aspekter er også mangelfullt utforsket. Dette gjelder ikke bare tvangsaspektene, men også for eksempel hvordan tiltak for orden på posten påvirker behandlingsrelasjoner og toleranse for atferd.

Det kunnskapsmessige grunnlaget for skjerming utgjøres av noen få behandlingsstudier og noen eldre bidrag fra døgnposter som delvis var annerledes når det gjelder pasientsammensetning, organisering og praksis enn postene i dagens psykiske helsevern. Dette skaper en diskrepans mellom skjermingsmetodens utbredte bruk og foreløpig kunnskapsgrunnlag. Det er derfor i dag umulig å konkludere om effekten av skjerming.

Det er behov for evaluering av skjermingsmetoden med egnede metoder for måling av innhold, virkninger og hvordan pasientene opplever det. Det nasjonale akuttnettverket utvikler nå et kunnskapsbasert og operasjonalisert måleverktøy for skjerming for å bidra til slik evaluering og forskning (41). 


\section{Reidun Norvoll (f. 1961)}

er sykepleier og dr.polit. i sosiologi, med en avhandling om skjerming. Hun er for tiden postdoktor.

Forfatter har fylt ut ICMJE-skjemaet og oppgir ingen interessekonflikter.

\section{Torleif Ruud (f. 1949)}

er professor i psykiatri og avdelingssjef. Forfatter har fylt ut ICMJE-skjemaet og oppgir ingen interessekonflikter.

\section{Torfinn Hynnekleiv (f. 1956)}

er overlege.

Forfatter har fylt ut ICMJE-skjemaet og oppgir ingen interessekonflikter.

\section{Litteratur}

1. Norvoll R. Det lukkede rom: bruk av skjerming som behandling og kontroll i psykiatriske akuttposter. Oslo: Universitetet i Oslo, 2007.

2. Bowers L, Alexander J, Simpson A et al. Cultures of psychiatry and the professional socialization process: the case of containment methods for disturbed patients. Nurse Educ Today 2004; 24: 435-42.

3. Poulsen HD Søndergård L, Hansen C et al. Psykiatriske patienters oplevelse af ophold i skærmede enheder. Ugeskr Læger 2005; 167: 509-13.

4. Vaaler A. Effects of a psychiatric intensive care unit in an acute psychiatric ward. Trondheim: Norges teknisk-naturvitenskapelige universitet 2007.

5. Vaaler AE, Iversen VC, Morken G et al. Short-term prediction of threatening and violent behaviour in an Acute Psychiatric Intensive Care Unit based on patient and environment characteristics. BMC Psychiatry 2011; 11: 44.

6. Bjørkly S. Open-area seclusion in the long-term treatment of aggressive and disruptive psychotic patients, an introduction to a ward procedure. Psychol Rep 1995; 76: 147-57.

7. Larsen IB, Terkelsen TB. Coercion in a locked psychiatric ward: perspectives of patients and staff. Nurs Ethics 2013; 21: 426-36.

8. Bremnes R, Lilleeng S, Pedersen PB. Bruk av tvang i psykisk helsevern for voksne i 2011, Oslo: Helsedirektoratet, 2012.

9. Husum TL, Bjørngaard JH, Finset A et al. A crosssectional prospective study of seclusion, restraint and involuntary medication in acute psychiatric wards: patient, staff and ward characteristics. BMC Health Serv Res 2010; 10: 89.

10. Ruud T, Gråwe RW, Hatling T. Akuttpsykiatrisk behandling i Norge: resultater fra en multisenterstudie. Report No.: A310. Trondheim: SINTEF Helse, 2006.

11. Bjørkly S, Knutzen M, Furre A, et al. Innsamling og analyse av data om bruk av tvangsmidler og vedtak om skjerming i det psykiske helsevernet for voksne i 2009. Oslo: Kompetansesenter for sikkerhets-, fengsels- og rettspsykiatri, Helse Sør-Øst, 2009.

12. Norvoll R, Hatling T, Hem K-G et al. Det er nå det begynner! Hovedrapport fra prosjektet «Brukerorienterte alternativer til tvang i sykehus» (BAT). Report No.: A8450. Trondheim: SINTEF Helse, 2008

13. Gunderson J, Will O, Mosher L. Principles and practice of milieu therapy. New York: Jason Aronson, 1983

14. Friis S. The ward atmosphere; a crucial dimension of inpatient settings: measurement, clinical rele- vance and some influencing factors: an empirical study. Oslo: Universitetet i Oslo, 1984

15. Løkensgard I. Psykiatrisk sykepleielære: generell del. Oslo: Universitetsforlaget, 1977.

16. Vaglum P, Jørstad J, Karterud S. Institusjonsbehandling i moderne psykiatri: fra et gruppeorientert til et individorientert terapeutisk samfunn. Oslo: Universitetsforlaget, 1984

17. Vaglum $P$, Friis $S$, Karterud S. Why are the results of milieu therapy for schizophrenic patients contradictory? An analysis based on four empirical studies Yale J Biol Med 1985: 58: 349-61.

18. Hummelvoll JK. Helt - ikke stykkevis og delt: synspunkter på psykiatrisk sykepleie. Oslo: Ad Notam Gyldendal, 1986

19. Strand L. Fra kaos mot samling, mestring og helhet: psykiatrisk sykepleie til psykotiske pasienter. Oslo: Gyldendal, 1990.

20. Høyer G, Drange H. Bruk av tvangsmidler i norske psykiatriske institusjoner. Tidsskr Nor Lægeforen 1991: 111: $585-8$

21. Haaland T, Thorsen GR, Brathetland O et al. Miljøterapi: en modell for tenkning, holdning og handling i en psykiatrisk institusjon. Stavanger: Stiftelsen Psykiatrisk Opplysning, 1998.

22. Holte J. «Som en livbøye i et opprørt hav ...»: skjer ming - en teoretisk begrunnelse og praktisk gjennomføring. Report No.: 82-7671-154-5. Elverum: Høgskolen i Hedmark, 2001

23. Vatne S. Korrigere og anerkjenne: sykepleieres rasjonale for grensesetting i en akuttpsykiatrisk behandlingspost. Oslo: Universitetet i Oslo, 2003.

24. Sørgaard KW. Patients' perception of coercion in acute psychiatric wards. An intervention study. Nord J Psychiatry 2004: 58: 299-304.

25. Karlsson B. Mani som fenomen og lidelse: pasientog personalerfaringer som grunnlag for kunnskapsutvikling i psykiatrisk sykepleie. Oslo: Universitetet i Oslo, 2004

26. Gamme WI. Skjerming med brukermedvirkning kan endring av skjermingspraksis øke pasienters tilfredshet? Tidsskrift for psykisk helsearbeid 2009; nr. 3: 241-9.

27. Bjerkan A-M, Lilleeng S, Pedersen PB. Brukerundersøkelse blant døgnpasienter i psykisk helsevern for voksne, $2003 \mathrm{og} 2007$. Report No. 978-82-14-04784-4. Trondheim: SINTEF, Tekno logi og samfunn, Helsetjenesteforskning, 2009.

28. Malt U, Retterstøl N. Dahl A. Lærebok i psykiatri. Oslo: Gyldendal, 2003.

29. Astrup C. Retterstøl N, Dahl A. Gaustad sykehus 125 år. Det psykiatriske sykehus i dag: fra enhet til mangfold. Oslo: Universitetsforlaget, 1980.

30. Vaglum P, Karterud S, Friis S. Fra et gruppeorientert til et individorientert terapeutisk samfunn for psykotiske pasienter: bakgrunn for forandringene. Målsetting og prinsipper for det nye behandlingsprogram. I: Vaglum P. Karterud S, Jørstad J, red. Institusjonsbehandling i moderne psykiatri. Fra et gruppeorientert til et individorientert terapeutisk samfunn. Oslo: Universitetsforlaget, 1984: 87-104

31. Friis S. Hvilken kunnskap har vi om hva slags behandlingsmiljø som er gunstig for ulike type pasienter? I: Vaglum P, Karterud S, Jørstad J, red Institusjonsbehandling i moderne psykiatri. Fra e gruppeorientert til et individorientert terapeutisk samfunn. Oslo: Universitetsforlaget, 1984: 45-56.

32. Hummelvoll JK, Severinsson E. Coping with everyday reality: mental health professionals' reflections on the care provided in an acute psychiatric ward. Aust N Z J Ment Health Nurs 2001; 10 : $156-66$.

33. Andersen K. Skjerming som metode i akuttpsykiatrisk avdeling: en studie av noen sykepleieres erfaringer. Oslo: Universitetet i Oslo, 2011.

34. Jensen $\emptyset$. Virksomme faktorer i akuttpsykiatri. Drammen: Høgskolen i Buskerud, 2008.

35. Lorentzen S, von Krogh G, Island T. Problemer knyttet til skjerming av urolige pasienter. I: Vaglum P. Karterud S, Jørstad J, red. Institusjonsbehand- ling i moderne psykiatri. Fra et gruppeorientert til et individorientert terapeutisk samfunn. Oslo: Universitetsforlaget, 1984: 204-12

36. Norges offentlige utredninger. Lov om psykisk helsevern uten eget samtykke. NOU 1988: 8.

37. Haugom EW. En kvalitativ studie av hvordan skjer ming beskrives og vurderes av miljøpersonal ved psykiatriske sykehus. Elverum: Høgskolen i Hedmark, 2013

38. Vaaler AE, Morken G, Linaker OM. Effects of different interior decorations in the seclusion area of a psychiatric acute ward. Nord J Psychiatry 2005: 59: $19-24$

39. Vaaler AE, Morken G, Fløvig JC et al. Substance abuse and recovery in a Psychiatric Intensive Care Unit. Gen Hosp Psychiatry 2006; 28: 65-70.

40. Vaaler AE, Morken G, Fløvig JC et al. Effects of a psychiatric intensive care unit in an acute psychiatric department. Nord J Psychiatry 2006; 60: $144-9$

41. Ruud T. Hynnekleiv T. Hva er skjerming? Prosjekt for utvikling av kunnskapsbasert og pålitelig måling av skjerming i døgnavdelinger i psykisk helsevern. Prosjektbeskrivelse 9.8.2012. www.akuttnettverket.no/ /media/Files/Skjerming/ Skjermingsprosjektbeskrivelse\%2009aug2012.ashx (21.1.2014)

Mottatt 3.2. 2014, første revisjon innsendt 8.5 2014, godkjent 23.9. 2014. Redaktør: Tor Rosness. 